\title{
HUBUNGAN SUPERVISI AKADEMIK DAN KEPEMIMPINAN KEPALA SEKOLAH DENGAN KOMPETENSI PROFESIONAL GURU SDN DI MARABAHAN KABUPATEN BARITO
}

\author{
Indriati Wiratin \\ Pascasarjana Manajemen Pendidikan \\ Universitas Islam Kalimantan Muhammad Arsyad Al Banjari \\ rindri299@gmail.com
}

\begin{abstract}
ABSTRAK
penelitian ini bertujuan (1) untuk mengetahui hubungan antara supervise akademik dengan kompetensi profesional guru SDN di Marabahan Kabupaten Barito Kuala. (2) Untuk mengetahui hubungan antara kepemimpinan kepala sekolah dengan kompetensi professional guru SDN di Marabahan Kabupaten Barito Kuala. (3) untuk mengetahui hubungan supervise akademik dan kepemimpinan kepala sekolah dengan kompetensi profesional guru SDN di Marabahan Kabupaten Barito Kuala. Penelitian menggunakan metode deskriftif korelasional, dengan populasi penelitian berjumlah 115 orang. Jumlah sampel penelitian yaitu sebanyak 85 orang. Hasil penelitin dismpulkan: (1) Terdapat hubungan yang positif dan signifikan antara supervise akademik denga kompetensi professional guru SDN di Marabahan Kabupaten Barito Kuala. (2) Terdapat hubungan yang positif dan signifikan antara kepemimpinan kepala sekolah dengan kompetensi professional guru SDN di Marabahan Kabupaten Barito Kuala. (3) Terdapat hubungan secara bersamasama yang positif dan signifikan antara supervise akademik dan kepemimpinan kepala sekolah dengan kompetensi profesional guru SDN di Marabahan Kabupaten Barito Kuala. Disarankan untuk melakukan penelitian serupa dengan subjek penelitian yang lebih luas.
\end{abstract}

Kata Kunci : Supervise Akademik, Kepemimpinan Kepala Sekolah dan, Profesional Guru

\begin{abstract}
This study aims (1) to determine the relationship between academic supervision and the professional competence of SDN teachers in Marabahan, Barito Kuala Regency. (2) To find out the relationship between the principal's leadership and the professional competence of SDN teachers in Marabahan, Barito Kuala Regency. (3) to determine the relationship between academic supervision and principal leadership with the professional competence of SDN teachers in Marabahan, Barito Kuala Regency. The study used a correlational descriptive method, with a research population of 115 people. The number of research samples is as many as 85 people. The results of the study were concluded: (1) There is a positive and significant relationship between academic supervision and the professional competence of SDN teachers in Marabahan, Barito Kuala Regency. (2) There is a positive and significant relationship between the principal's leadership and the professional competence of SDN teachers in Marabahan, Barito Kuala Regency. (3) There is a jointly positive and significant relationship between academic supervision and principal's leadership with the professional competence of SDN teachers in Marabahan, Barito Kuala Regency. It is recommended to carry out similar research with a wider range of research subjects.
\end{abstract}

Keywords: Academic Supervision, Principal Leadership and Teacher Professionals 


\section{PENDAHULUAN}

Pendidikan merupakan sumber daya utama bagi kemajuan suatu bangsa, untuk itu pendidikan perlu dibangun dan dikembangkan agar mampu menghasilkan sumber daya manusia yang unggul. Dalam konteks tersebut, paradigma pendidikan baru mensyaratkan pentingnya membangun kualitas pendidikan di sekolah. Karena sekolah merupakan salah satu bentuk peradaban modern dalam membangun dan mengembangkan karakter manusia seutuhnya. Membangun sekolah yang bermutu melibatkan banyak faktor, dimana kepala sekolah merupakan salah satu faktor stratejik dan paling penting dalam mengembangkan sekolah yang bermutu. Selain itukepala sekolah dihadapkan pada tantangan dan tuntutan yang semakin dinamis dari stakeholders, terutama dalam perannya sebagai nakhoda yang menentukan arah dan tujuan yang akan dicapai oleh sekolah.

Menurut Mulyasa (2005:65) sedikitnya terdapat tujuh kesalahan yang sering dilakukan guru dalam pembelajaran. Kesalahan tersebut diantaranya adalah mengambil jalan pintas dalam pembelajaran, menunggu peserta didik berperilaku negatif, menggunakan destruktif discipline, mengabaikan kebutuhan-kebutuhan khusus(perbedaan individu) peserta didik, merasa diri paling pandai di kelasnya, tidak adil (diskriminatif), serta memaksa hak peserta didik. Alasan klasiknya guru belum melaksanakan tugas profesionalnya sebagai tenaga pendidik adalah gaji dan kesejahteraan guru yang rendah membuat para guru seakanakan tak mampu untuk menghadapi tuntutan yang berat yang dibebankan kepadanya. Mereka selalu terpuruk dan seakan-akan tak berdaya menghadapi hempasan badai keras globalisasi yang melunturkan semangat pengabdian mereka. Sejalan dengan pendapat tersebutdiatas, pembelajaran menurut pandangan konstruktivisme adalah:pembelajaran dibangun oleh manusia sedikit demi sedikit, yang hasilnya diperluas melalui konteks yang terbatas (sempit) dan tidak sekonyong-konyong. Pembelajaran bukanlah seperangkat fakta, konsep atau kaidah yang siap untuk diambil dan diingat.Manusia harus mengkonstruksi pembelajaran itu dan membentuk makna melalui pengalaman nyata(Depdiknas,

2003:11). Menurut Kasmadi (1993:24) pelaksanaan kegiatan belajar mengajar dimana pengajar masih memegang peran yang sangat dominan, pengajar banyak ceramah (telling method) dan kurang membantu pengembangan aktivitas murid, sehingga keterampilan yang dimiliki anak terbatas. tidak dipungkiri bahwa dilapangan masih banyak guru yang masih melakukan cara seperti pendapat diatas, dan diakui bahwa banyak faktor penyebabnya sehingga dapat dilihat akibat yang timbul pada peserta didik, sering dijumpai siswa belajar hanya untuk memenuhi kewajiban pula, masuk kelas tanpa persiapan, siswa merasa terkekang, membenci guru karena tidak suka gaya mengajarnya, bolos, tidak mengerjakan tugas yang diberikan guru, takut berhadapan dengan mata pelajaran tertentu, merasa tersisihkan karena tidak dihargai pendapatnya, hak mereka merasa dipenjara, terkekang sehingga berdampak pada hilangnya motivasi belajar, suasana belajar menjadi monoton, dan akhirnya kualitas pun menjadi pertanyaan. Dari permasalahan tersebut, guru mempunyai tanggung jawab terhadap peningkatan mutu mengajar di sekolah karena guru sebagai ujung tombak dilapangan (di kelas) dan bersentuhan langsung dengan siswa dalam proses pembelajaran. Guru mempunyai tugas dan tanggung jawab yang sangat berat terhadap kemajuan dan peningkatan kompetensi siswa, dimana hasilnya akan terlihat dari jumlah siswa yang lulus dan tidak lulus. dengan demikian tangung jawab peningkatan mutu pendidikan di sekolah, selalu dibebankan kepada guru. sejalan dengan pendapat Hidayat (2015), yang menyatakan bahwa kepala sekolah mempunyai tugas mengembangkan kinerja personel, terutama meningkatkan profesional guru. Menurut Utami (2003:1) Guru merupakan faktor utama dalam proses pendidikan. Meskipun fasilitas pendidikannya lengkap dan canggih, namun bila tidak ditunjang oleh keberadaan guru yang berkualitas, maka mustahil akan menimbulkan proses belajar mengajar yang maksimal. Proses pembelajaran akan berlangsung dengan baik apabila didukung oleh guru yang mempunyai kompetensi dan kinerja yang tinggi, karena guru merupakan ujung tombak dan pelaksana terdepanpendidikan anak di sekolah. Kegiatan pokok supervisi adalah melakukan pembinaan kepada sekolah pada umunya dan guru pada khususnya.

Dahulu istilah yang banyak digunakan untuk kegiatan serupa ini adalah inpeksi, istilah ini mempunyai konotasi mencari-cari kesalahan orang dalam melaksanakan kegiatan, pemeriksaanadalah kegiatan seolaholah hanya 
melihat apa yang terjadi dalam kegiatan, belum tampak adanya upaya penilaian, pengawasan atau penilikan adalah kegiatan bukan saja melihat apa yang terjadi dalam kegiatan keduanya seperti pemeriksaan, tetapi sudah mengadakan penilaian, yaitu mengidentifikasi halhal yang sudah baik sesuai yang diharapkan dan hal-hal yang belum sesuai dengan harapan. Supervisi merupakan istilah yang dalam rumpun pengawasan tetapi sifatnya lebih human, manusiawi. Di dalam kegiatan supervisi, pelaksanaan bukan mencaricari kesalahan tetapi lebih banyak mengandung unsur pembinaan, agar kondisi pekerjaan yang sedang disupervisi dapat diketahui kekurangannya (bukan sematamata kesalahannya) untuk diberitahu bagian yang perlu diperbaiki (Arikunto, 2004: 1).

Menurut Purwanto (2005:76) supervisi adalah aktivitas pembinaan yang direncanakan untuk membantu para guru dan pegawai dalam melakukan pekerjaan secara efektif. Dengan kepemimpinan kepala sekolah tersebut maka diharapkan apa yang menjadi esensi supervisi pendidikan dapat diterapkan di sekolah.

Arikunto (2004:13) mengemukakan tujuan utama kegiatan supervisi adalah meningkatan kualitas pembelajaran, yang harapan akhirnya juga pada prestasi belajar siswa. Peningkatan tersebut tidak hanya mengenai satu aspek saja, tetapi semua unsur yang terkait dengan proses pembelajaran, antara lain siswa itu sendiri, guru dan personel lain, peralatan, maupun lingkungan tempat belajar. Gambaran secara umum pelaksanaan supervisi di SDN

Marabahan belum maksimal, dari hasil supervisi silang yang dilakukan kepala sekolah di Kecamatan Marabahan Kabupaten Barito Kuala, masih banyak guru yang belum mampu mengembangkan metode pembelajaran yang kreatif dan efektif untuk menghasilkan peserta didik yang berkualitas. Hal ini dikarenakan frekwensi supervisi yang jarang dilakukan oleh kepala sekolah karena alasan belum memahami tehnik dan prosedur supervisi dan instrumen yang digunakan. Supervisi selama ini dianggap hanya mencari-cari kelemahan/kesalahan guru.

Berdasarkan uraian diatas menunjukkan bahwa kepemimpinan kepala sekolah adalah melakukan pembinaan kepada sekolah pada umunya dan guru pada khususnya agar kualitas pembelajaran meningkat. Sebagai dampak meningkatnya kualitas pembelajaran, tentu dapat meningkatkan prestasi belajar siswa.
Sehingga dapat diduga bahwa meningkatnya angka kelulusan Ujian

Sekolah SDN di Kecamatan

Marabahan Kabupaten Barito Kuala disebabkan oleh keberhasilan siswa dalam memperoleh ilmu pengetahuan dan keterampilan di sekolah, berati bahwa supervisi yang dilakukan oleh kepala sekolah terhadapguru sudah sesuai dengan tujuannya. Atas dasar pemikiran tersebut, peneliti merasa tertarik untuk mengadakan penelitian tentang " Hubungan Supervisi Akademik dan Kepemimpinan Kepala Sekolah dengan Kompetensi Profesional Guru SDN di Marabahan Kabupaten Barito Kuala”. 


\section{METODE}

Methodology Metode yang digunakan dalam penelitian ini adalah metode deskriptif. Penelitian ini pada dasarnya bertujuan untuk memperoleh gambaran yang jelas mengenai seberapa besar Hubungan dari variabel perilaku kepemimpinan kepala sekolah $\left(\mathrm{X}_{1}\right)$, dan variabel Kepemimpinan Kepala Sekolah $\left(\mathrm{X}_{2}\right)$, terhadap Kompetensi Profesional Guru pada SDN di Marabahan Kabupaten Barito Kuala Arikunto(2006:309) dan Rakhmat (2006: 81) menjelaskan bahwa penelitian deskriptif dimaksud untuk mengumpulkan informasi mengenaistatus suatu gejala yang ada, yaitu keadaan menurut apa adanya pada saat penelitian dilakukan.

Sugiyono (2009:56) menyatakan bahwa penelitian deskriptif adalah penelitian yang mempunyai tujuan untuk memecahkan masalah yang ada pada masa sekarang dan bersifat tidak terbatas pada pengumpulan dan penyusunan data saja melainkan sampai kepada kegiatan analisis dan interprestasi data. Penelitian ini melibatkan tiga variabel Supervisi

\section{Akademik $\left(\mathrm{X}_{1}\right)$, variabel}

Kepemimpinan Kepala Sekolah $\left(\mathrm{X}_{2}\right)$ dan variabel Kompetensi Profesional Guru (Y). Untuk populasi Sugiyono (2008:92) mendefinisikan populasi adalah generalisasi yang terdidri atas; objek/subjek yang mempunyai kualitas dan karakteristik tertentu yang ditetapkan oleh peneliti untuk dipelajari dan kemudian ditarik kesimpulannya. Jadi populasi bukan hanya orang, tetapi juga objek dan benda-benda alam yang lain. Arikunto (2002: 108) menyatakan populasi juga bukan hanya sekedar jumlah yan ada pada objek/subjek yang dipelajari, tetapi meliputi seluruh karakteristik/sifat yang dimiliki oleh subyek atau obyek itu.Populasi adalah keseluruhan subjek penelitian.

Sedangkan Sudjana (2001:6) berpendapat bahwa populasi mengandung arti sebagai totalitas nilai hasil mengukur atau menghitung baik kuantitatif maupun kualitatif darikarakteristik tertentu mengenai sekumpulan objek yang lengkap dan jelas yang ingin dipelajari sifatsifatnya, sedangkan sampel adalah sebagian yang diambil dari populasi. Pengertian ini juga hampir sama seperti yang dikemukakan Furqon (2002: 135), dikatakan populasi dapat didefinisikan sebagai sekumpulan objek, orang atau keadaan yang paling tidak meniliki satu karakteristik umum yang sama, sekelornpok yang sama digeneralisasikan untuk memperoleh hasil dalam penelitian.

Sedangkan Sudjana (2001:6) berpendapat bahwa populasi mengandung arti sebagai totalitas nilai hasil mengukur atau menghitung baik kuantitatif maupun kualitatif darikarakteristik tertentu mengenai sekumpulan objek yang lengkap dan jelas yang ingin dipelajari sifatsifatnya, sedangkan sampel adalah sebagian yang diambil dari populasi. Pengertian ini juga hampir sama seperti yang dikemukakan Furqon (2002: 135), dikatakan populasi dapat didefinisikan sebagai sekumpulan objek, orang atau keadaan yang paling tidak meniliki satu karakteristik umum yang sama, sekelornpok yang sama digeneralisasikan untuk memperoleh hasil dalam penelitian.

Populasi dalam penelitian ini adalah semua guru yang berstatus PNS yang telah memiliki masa kerja > 5 tahun pada SDN di Marabahan Kabupaten Barito Kuala yang berjumlah 115 orang guru berstatus PNS yang tersebar di 10 Sekolah Dasar Negeri di wilayah UPTD Dinas Pendidikan Marabahan Kabupaten Barito Kuala. Dengan demikian, 115 guru yang berstatus PNS yang telah memiliki masa kerja > 5 dari 10 SDN inilah yang dijadikan sebagai populasi dalam penelitian ini.

Sampel adalah bagian dari jumlah dan karakteristik yang dimiliki oleh populasi (Sugiyono, 2006: 93). Arikunto (2007, 110) menyatakan bahwa sampel dapat diambil dari sebagian yang merupakan wakil dari populasi. Penentuan jumlah sampel dilakukan dengan menggunakan teknik ProportionalRandom Sampling yaitu pengambilan sampel dari anggota populasi secara acak dan proporsional (Arikunto, 2007). Karena terkadang, terjadi perbedaan antara hasil sampel dan populasi, yang mengakibatkan sampling error, maka untuk mengurangi prosentase kesalahan, dalam penelitian ini digunakan ukuran sampel oleh Slovin (Riduwan, 2010: 65) jumlah sampel penelitian untuk sekolah ada 10 SDN, sampel guru sebanyak 115 guru (responden), dan responden uji coba instrument penelitian sebanyak 30 orang guru (responden) yang berada di tempat penelitian dan termasuk dalam populasi penelitian namun diluar dari sampel penelitian.Uji coba (try out) instrumen dilaksanakan pada 30 guru yang tidak termasuk sampel penelitian yang terdiri dari guru SDN Marabahan 1 sebanyak 4 orang, guru SDN Marabahan 2 sebanyak 4 orang, guru SDN Marabahan 3 sebanyak 2 orang, guru SDN Ulu Benteng 2 sebanyak 6 orang, SDN Penghulu sebanyak 2 orang, guru SDN Bagus 1 sebanyak 2 orang, guru SDN Bagus 2 sebanyak 2 orang, SDN Ulu Benteng 1 sebanyak 3 orang, SDN Ulu Benteng 3 sebanyak 3 orang, SDN Ulu Benteng 5 sebanyak 2 orang.

Penelitian ini menggunakan kuesioner untuk menjaring data tentang Supervisi Akademik, Dipublikasikan Oleh: 
Kepemimpinan Kepala Sekolah, dan Kompetensi Profesional Guru pada SDN di Marabahan Kabupaten Barito Kuala. lnstrumen Supervisi Akademik ini berupa kuesioner (angket) dengan

\section{HASIL DAN PEMBAHASAN}

Supervisi Akademik

Menggunakan model skala Likert. Alternatif pilihan jawaban yang digunakan masing-masing kuesioner adalah berupa skala Likert, yang terdiri dari lima altenatif jawaban. Sedangkan alternatif jawabannya adalah: Selalu (SL), Sering (SR), Kadang-kadang (KK), Jarang (JR), dan Tidak pernah (TP). Penskoran untuk pertanyaan atau pernyataan positif adalah $\mathrm{SL}=5$, $\mathrm{SR}=4, \quad \mathrm{KK}=3$, JR=2, dan $\mathrm{TP}=1$, skor untuk pertanyaan atau pernyataan negatif adalah $\mathrm{SL}=1$, $\mathrm{SR}=2, \mathrm{KK}=3, \mathrm{JR}=4$, dan $\mathrm{TP}=5$. Instrumen kepemimpinan kepala sekolah ini berupa kuesioner (angket) dengan menggunakan model skala

Likert. Alternatif pilihan jawaban yang digunakan masing-masing kuesioner adalah berupa skala Likert, yang terdiri dari lima altenatif jawaban. Sedangkan altematif jawabannya adalah: Selalu (SL), Sering (SR), Kadang-kadang (KK), Jarang (JR) dan Tidak pernah (TP). Penskoran untuk pertanyaan atau pernyataan positif adalah $\mathrm{SL}=5$, $\mathrm{SR}=4$, $\mathrm{KK}=3$, JR=2, dan $\mathrm{TP}=1$, skor untuk pertanyaan atau pernyataan negatif adalah $\mathrm{SL}=1$, $\mathrm{SR}=2, \mathrm{KK}=3, \mathrm{JR}=4$, dan

$\mathrm{TP}=5$.Instrumen Kompetensi

Profesional Guru ini dijabarkan dalam beberapa indikator.Dari indikator tersebut, dibuat berupa pernyataan dan pertanyaan dengancara memilih alternatif yang disediakan. Setiap indikator dijabarkan dalam bentuk penyataan/pertanyaan. Kemudian setelah diujicobakandiharapkan tetap mewakili masing-masing indicator.

Berdasarkan data hasil penelitian, ringkasan jawaban responden tentang Supervisi Akademik SDN di Marabahan Kabupaten Barito Kuala.

Selanjutnya berdasarkan skor median dan standar deviasi dapat dibuat klasifikasi Supervisi Akademik di SDN Marabahan Kabupaten Barito Kuala, yaitu sebagai berikut. Berdasarkan data hasil penelitian, ringkasan jawaban responden tentang

Supervisi Akademik SDN di

Marabahan Kabupaten Barito Kuala secara ringkas disajikan pada tabel berikut.
Tabel Tingkat Supervisi Akademik

\begin{tabular}{|c|c|c|c|c|}
\hline $\begin{array}{c}\text { N } \\
\text { o }\end{array}$ & $\begin{array}{l}\text { Interv } \\
\text { a } \\
1\end{array}$ & $\begin{array}{c}\text { Frekuen } \\
\text { s i } \\
\geq 121\end{array}$ & $\begin{array}{c}\text { Persenta } \\
\text { s e }\end{array}$ & $\begin{array}{c}\text { Klasifika } \\
\text { s i }\end{array}$ \\
\hline 2. & $\begin{array}{c}77 \leq \\
\text { Skor } \\
< \\
121\end{array}$ & 0 & $0 \%$ & Tedang \\
\hline 3. & $\begin{array}{c}\text { Skor } \\
\leq 77\end{array}$ & 0 & $0 \%$ & Rendah \\
\hline & $\begin{array}{l}\text { Jumla } \\
\text { h }\end{array}$ & 85 & $100 \%$ & \\
\hline
\end{tabular}

Pada tabel di atas diketahui bahwa seluruh kegiatan Supervisi Akademik SDN di Marabahan Kabupaten Barito Kuala adalah berada pada klasifikasi tinggi dengan persentase sebesar $100 \%$. Sedangkan yang berada pada klasifikasi sedang dan klasifikasi rendah dengan persentase sebesar $0 \%$.

Adapun histogram yang menggambarkan bagaimana sebaran skor Supervisi Akademik di SDN Marabahan Kabupaten Barito Kuala dapat dilihat pada gambar berikut.

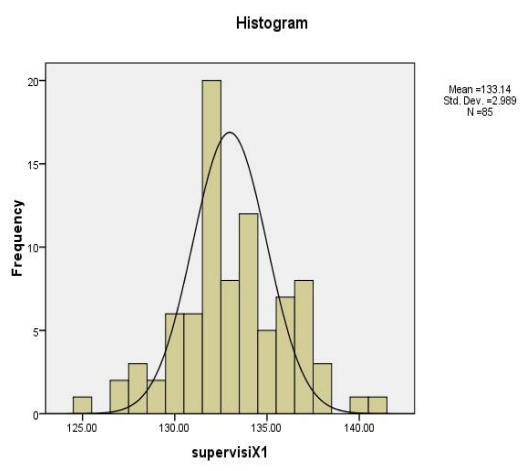

HistogramSkor Supervisi Akademik

3.2 Kepemimpinan Kepala Sekolah Berdasarkan data hasil penelitian tentang Kepemimpinan Kepala Sekolah SDN di Marabahan Kabupaten Barito Kualasecara ringkas disajikan pada tabel berikut.

Tabel Tingkat Kepemimpinan Kepala

Sekolah

\begin{tabular}{|l|c|l|l|c|}
\hline $\begin{array}{l}\text { No } \\
\text { 1. }\end{array}$ & $\begin{array}{c}\text { Interv } \\
\text { al }\end{array}$ & $\begin{array}{l}\text { Frekuen } \\
\text { si }\end{array}$ & $\begin{array}{l}\text { Persenta } \\
\text { se }\end{array}$ & $\begin{array}{c}\text { Klasifika } \\
\text { si }\end{array}$ \\
\hline 1. & $\begin{array}{c}\text { Skor } \\
\geq\end{array}$ & 100 & $100 \%$ & Tinggi \\
& 105 & & & \\
\hline
\end{tabular}




\begin{tabular}{|c|c|c|c|c|}
\hline 2. & $\begin{array}{c}81 \leq \\
\text { Skor } \\
< \\
105\end{array}$ & 0 & $0 \%$ & Sedang \\
\hline 3. & $\begin{array}{c}\text { Skor } \\
\leq \\
81\end{array}$ & 0 & $0 \%$ & Rendah \\
& $\begin{array}{c}\text { Jumla } \\
\text { h }\end{array}$ & 85 & $100 \%$ & \\
\hline
\end{tabular}

Pada tabel di atas diketahui bahwa sebagian besar Kepemimpinan Kepala

Sekolah SDN di Marabahan

Kabupaten Barito Kuala adalah berada pada klasifikasi tinggi dengan persentase sebesar $100 \%$. Sedangkan pada klasifikasi sedang dan klasifikasi rendah dengan persentase sebesar $0 \%$.

Adapun histogram yang menggambarkan sebaran skor jawaban responden tentang Kepemimpinan Kepala Sekolah SDN di Marabahan Kabupaten Barito Kuala dapat dilihat pada gambar berikut.

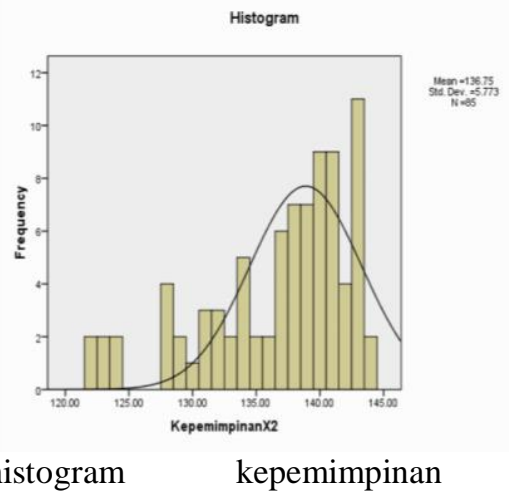

kepala sekolah.

3.3 Kompetensi Profesional Guru.

Berdasarkan data hasil penelitian, ringkasan jawaban responden tentang Kompetensi Profesional Guru SDN di Marabahan Kabupaten Barito Kuala secara ringkas disajikan dalam bentuk tabel distribusi frekuensi skor jawaban responden tentang Kompetensi Profesional Guru SDN di Marabahan Kabupaten Barito Kuala, yaitu sebagai berikut.

Tingkat Kompetensi Profesional Guru

\begin{tabular}{|l|c|l|l|l|}
\hline $\begin{array}{l}\text { No } \\
\cdot\end{array}$ & $\begin{array}{c}\text { Interv } \\
\text { al }\end{array}$ & $\begin{array}{l}\text { Frekuen } \\
\text { si }\end{array}$ & $\begin{array}{l}\text { Persenta } \\
\text { se }\end{array}$ & $\begin{array}{l}\text { Klasifik } \\
\text { asi }\end{array}$ \\
\hline 1. & $\begin{array}{c}\text { Skor } \\
\geq\end{array}$ & 22 & $25,88 \%$ & Tinggi \\
& $\begin{array}{c} \\
106\end{array}$ & & & \\
\hline
\end{tabular}

\begin{tabular}{|c|c|c|c|c|}
\hline 2. & $\begin{array}{c}68 \leq \\
\text { Skor } \\
<\end{array}$ & 63 & $74,12 \%$ & Sedang \\
& 106 & & & \\
\hline 3. & $\begin{array}{c}\text { Skor } \\
\leq \\
68\end{array}$ & 0 & $0 \%$ & Rendah \\
& $\begin{array}{c}\text { Jumla } \\
\text { h }\end{array}$ & 85 & $100 \%$ & \\
\hline
\end{tabular}

Berdasarkan tabel tersebut diketahui bahwa seluruh besar Kompetensi Profesional Guru SDN di Marabahan Kabupaten Barito Kuala adalah berada pada klasifikasi sedang dengan persentase sebesar 74,12\%.

Sedangkan yang berada pada klasifikasi tinggi dengan persentase $25,88 \%$ dan klasifikasi rendah dengan persentase sebesar $0 \%$.

Adapun histogram yang

menggambarkan sebaran skor jawaban responden tentang Kompetensi Profesional Guru SDN di Marabahan Kabupaten Barito Kualadapat dilihat pada gambar berikut.

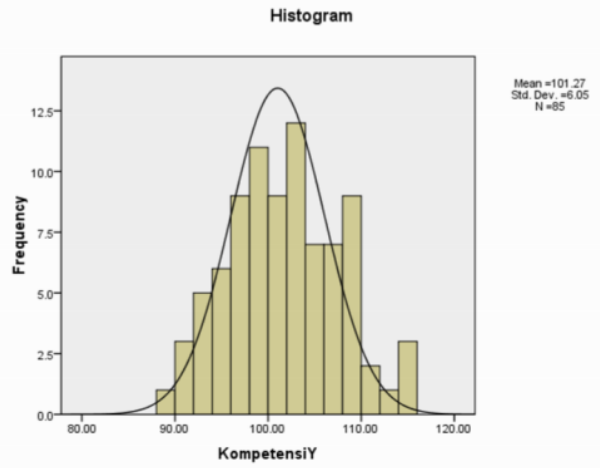

Histogram skor kompeensi

professional guru 3.4 Pengujian Hipotesis Penelitian

\section{Hubungan Supervisi Akademik dengan \\ Kompetensi \\ Profesional Guru}

Guna menentukan ada atau tidaknya Hubungan Supervisi Akademik dengan Kompetensi Profesional Guru SDN di Marabahan Kabupaten Barito Kuala ditentukan dengan menggunakan teknik analisis korelasi sederhana. Sedangkan rumusan hipotesis yang diajukan untuk menggambarkan hubungan tersebut adalah sebagai berikut.

Ho : Tidak terdapat Hubungan Supervisi Akademik dengan Kompetensi Profesional Guru SDN di Marabahan Kabupaten Barito Kuala. 
Ha : Terdapat Hubungan Supervisi Akademik dengan Kompetensi Profesional Guru SDN di Marabahan Kabupaten Barito Kuala.

dari Supervisi Akademik dengan Kompetensi Profesional Guru adalah sebesar 0,050 dan signifikansinya adalah 0,047. karena nilai dari SIG $=0,047<0,05$, maka menerima Ha. Sehingga dapat diambil kesimpulan bahwa "Terdapat Hubungan Supervisi Akademik dengan Kompetensi Profesional Guru SDN di Marabahan Kabupaten Barito Kuala".

\section{Hubungan Kepemimpinan Kepala Sekolah dengan Kompetensi \\ Profesional Guru}

Untuk menentukan ada atau tidaknya Hubungan Kepemimpinan Kepala Sekolah dengan Kompetensi Profesional Guru SDN di Marabahan Kabupaten Barito Kuala ditentukan dengan menggunakan teknik analisis korelasi sederhana. Rumusan hipotesis yang diajukan untuk menggambarkan hubungan tersebut sebagai berikut.

Ho : Tidak terdapat Hubungan Kepemimpinan Kepala Sekolah dengan Kompetensi Profesional Guru SDN di Marabahan Kabupaten Barito Kuala.

Ha : Terdapat Hubungan Kepemimpinan Kepala Sekolah terhadap Kompetensi Profesional SDN di Marabahan Kabupaten Barito Kuala. nilai $S I G$ dari Kepemimpinan Kepala Sekolah dengan Kompetensi Profesional Guru SDN di Marabahan Kabupaten Barito Kuala adalah sebesar 0,016 dan signifikansinya adalah 0,05 . karena nilai dari $S I G=0,016<0,05$, maka menerima $\mathrm{Ho}$. Sehingga dengan ini dapat diambil kesimpulan bahwa "Terdapat Hubungan Kepemimpinan Kepala Sekolah dengan Kompetensi Profesional Guru SDN di Marabahan Kabupaten Barito Kuala”.

Hubungan Supervisi Akademik Dan Kepemimpinan Kepala Sekolah dengan Kompetensi Profesional Guru Untuk menentukan ada atau tidaknya Hubungan secara bersama-sama antara

Supervisi Akademik dan Kepemimpinan Kepala Sekolah dengan Kompetensi Profesional Guru SDN di Marabahan Kabupaten Barito

Kuala ditentukan dengan menggunakan teknik analisis korelasi berganda. Sedangkan rumusan hipotesis yang diajukan untuk menggambarkan Hubungan tersebut adalah sebagai berikut.
Ho : Tidak terdapat Hubungan Supervisi Akademik dan Kepemimpinan Kepala Sekolah dengan Kompetensi Profesional Guru SDN di Marabahan Kabupaten Barito Kuala.

$\mathrm{Ha}$ : Terdapat Hubungan Supervisi Akademik dan Kepemimpinan Kepala Sekolah dengan Kompetensi Profesional Guru SDN di Marabahan Kabupaten Barito Kuala. nilai SIG dari Supervisi Akademik dan Kepemimpinan Kepala Sekolah dengan Kompetensi

Profesional Guru SDN di Marabahan Kabupaten Barito Kuala adalah sebesar 0,0269 dan signifikansinya adalah 0,05 . karena nilai dari $S I G$ $=0,0269<0,05$, maka Ho ditolak dan menerima Ha. Sehingga dapat diambil kesimpulan bahwa "Terdapat Hubungan Supervisi Akademik dan Kepemimpinan Kepala Sekolah dengan Kompetensi Profesional Guru SDN di Marabahan Kabupaten Barito Kuala".

\section{KESIMPULAN}

Berdasarkan analisis data dan pembahasan dapat disimpulkan beberapa hasil penelitian sebagai berikut:

1. Terdapat hubungan yang positif dan signifikan antara Supervisi Akademik dengan Kompetensi Profesional guru SDN di Marabahan Kabupaten Barito Kuala.

2. Terdapat hubungan yang positif dan signifikan antara Kepemimpinan Kepala Sekolah dengan Kompetensi Profesional guru SDN di Marabahan Kabupaten Barito Kuala.

3. Terdapat hubungan secara bersama-sama yang positif dan signifikan antara Supervisi Akademik dan Kepemimpinan Kepala Sekolah dengan Kompetensi Profesional guru SDN di Marabahan Kabupaten Barito Kuala.

\section{DAFTAR PUSTAKA}

Arikunto, S. 2004. Dasar-dasar Supervisi Pendidikan. Jakarta : Rineka Cipta

Depdiknas. 2003. Undang-undang RI No. 20 Tahun 2003 Tentang

Sisdiknan. Jakarta : Depdiknas

Hidayat. 2015. Analisis Administrasi Manajamen dan Kepemimpinan

Pendidikan. Jakarta : Bumi Aksara

Kasmadi. 1993. Belajar dan

Mengajar. Bandung : Yrama Widya Mulyasa, E. 2005. Kepemimpinan Kepala Sekolah. Bandung : Aditama

Purwanto, M. N. 2006. Administrasi dan Supervisi Pendidikan, Cet. 7. Bandung : Rosdakarya

Dipublikasikan Oleh 
Utami, Neni. 2003. Kualitas dan Professionalisme.http://pikiranraky at.com (online) diakses pada 17

November 2020 